\title{
AFASIA AMNESTICA. CONSIDERAÇÕES A PROPÓSITO DE UM CASO
}

\author{
Spartaco Vizzotto * \\ AFonso SETTE JUNIOR** \\ Nelma ValdRighi *
}

\author{
STANISLAU KRINSKY * \\ Roberto TOMCHINSKY * \\ Walter Edgard Maffei ***
}

Descrita por Pitres na segunda metade do século passado, a afasia amnéstica logo mereceu a atenção dos pesquisadores, não só pela sua importância clínica mas também pelos elementos que vinha propiciar às diversas hipóteses teóricas sôbre os mecanismos da expressão verbal. Freqüentemente são usadas como sinônimas de afasia amnéstica as seguintes expressōes: amnésia verbal, afasia de formulação (Nielsen ${ }^{16}$ ), dismnésia de evocação verbal (Pitres, Bianchi, Rivi), afasia de nomeação (Eagleton ${ }^{4}$ ).

A importância prática do distúrbio é bem expressa por Nielsen ${ }^{16}$ (pág. 468): "Há sòmente uma forma de afasia que possui valor definido para localização em caso de neoplasma: a afasia amnéstica". Quase todos os autores chamam a atenção para a freqüência e precocidade com que êste distúrbio surge nos casos de abscessos originados do ouvido e nos tumores que atingem a parte posterior do lobo temporal. Eagleton ${ }^{4}$ afirma ser a afasia amnéstica freqüente nos abscessos têmporo-esfenoidais. Outro aspecto positivo é a facilidade da sua identificação; o fato de surgir muitas vêzes não complicada com outras formas de afasia torna-a de pronto identificável.

A importância teórica da afasia amnéstica advém da nitidez de sua manifestação e da dificuldade para a compreensão satisfatória do seu mecanismo.

Quanto à situação da afasia amnéstica em relação às outras formas de afasias, devemos salientar que, no consenso da maioria dos autores, ela ocupa um lugar independente. A maioria dos autores considera quatro formas de afasias: sensorial ou de recepção, motora ou de expressão, total ou mista e amnéstica. Sơmente alguns autores antigos não a admitiram como forma isolada e sim como aspecto parcial de afasia sensorial ou motora atenuada; assim pensaram Pierre Marie, Foix e Froment (cit. ${ }^{1}$. Déjérine, no entanto, conseguiu identificar alguns casos, convencendo-se de sua independência (cit. ${ }^{1}$ ). Só encontramos estatística de freqüência na casuística de Weisenburg e McBride ${ }^{19}$ (pág. 146) : 8,3\% (5 casos) do total de casos de afasia registrado pelos autores.

Trabalho do Hospital de Juqueri, apresentado ao Departamento de Neuro-Psiquiatria da Associaçāo Paulista de Medicina em 7 de fevereiro de 1955.

* Médicos psiquiatras; ** Neurocirurgião; *** Anátomo-patologista. 
Dos mais discutidos são o conceito e a delimitação da afasia amnéstica. Pitres (cit. ${ }^{1}$ ) descreveu-a como variedade de afasia em que está perturbada a evocação das palavras: o doente pode falar, escrever, mas é inibido pelo esquecimento das palavras e contorna a dificuldade por perifrases ou gestos explicativos, sendo o distúrbio evidenciado na prova de denominação de objetos. Pitres distinguia, ao lado dêste quadro, outro em que faltam ao doente os verbos em lugar dos substantivos - o que corresponde ao agramatismo de Pick - e ainda outro em que há esquecimento de uma lingua estrangeira, o que ocorre nos poliglotas.

Desde então inúmeros casos surgiram, publicados sob o rótulo de afasia amnéstica, nas mais variadas afeç̧ões cerebrais e nas mais diversas localizaçōes. Bianchi ${ }^{2}$, já em 1895, chamava a atenção para o fato de que grande parte dêsses casos nāo era de afasia amnéstica e sim de deficiência geral da memória de evocaçāo e da elaboração intelectual, freqüentemente observadas em psicoses por lesão cerebral como a demência senil, a paralisia geral, a moléstia de Pick e a de Alzheimer, a arteriosclerose cerebral e diversos outros quadros demenciais. Salientou Bianchi que na afasia amnéstica trata-se exclusivamente de "ausência de representação das imagens sensoriais da palavra" (pág. 122), distinguindo-a da afasia motora e da sensorial, no inicio ou na fase de remissão, das quais podem surgir fenômenos que grosseiramente se confundiriam com a afasia amnéstica. Não obstante o esclarecimento de Bianchi, continuam a ser publicados falsos casos dêste tipo de afasia, o que tem dificultado a sua delimitação conceitual e a determinação dos setores cerebrais por ela responsáveis.

Parece-nos que Kurt Goldstein ${ }^{7}$ se contradiz quando procura caracterizar os distúrbios essenciais da afasia amnéstica, no afā de provar sua teoria sôbre as afasias. Assim, em relação aos fenômenos afásicos produzidos por abscessos conseqüentes a infecçōes do ouvido que muitas vêzes atingem a área 37, afirma (pág. 67) que não se trata de afasia amnéstica, enquanto que mais adiante (pág. 290) escreve que essas são as formas características nos casos de lesōes focais. Goldstein não distingue claramente os distúrbios derivados da amnésia de evocação e do déficit da elaboração intelectual, pois êstes casos se prestam bem à demonstração de sua teoria segundo a qual a causa da afasia amnéstica repousa principalmente em um déficit da elaboração intelectual que êle chama de atitude abstrata (pág. 247); salienta, no entanto, a diferença essencial que há entre o que êle define como "linguagem automática" e "linguagem voluntária", sendo o distúrbio desta última a caracteristica da afasia amnéstica (pág. 59). Afirma Goldstein que as perturbações da linguagem automática caracterizam a afasia motora, na qual são freqüentes as parafasias, ausentes ou raras nas perturbações da linguagem voluntária (pág. 60 e 65). Goldstein separa a afasia amnéstica dessas afasias motoras, nas quais, além de freqüentes parafasias, há também dificuldade na repetição das palavras e na própria fala espontânea, e distingue-a da afasia sensorial, na qual há dificuldade na compreensão da linguagem falada. 
Von Monakow, citado por Nielsen ${ }^{16}$, também não distinguiu a afasia amnéstica dos quadros com déficit de memória generalizada. Nielsen ${ }^{16}$ (pág. 70) a distingue das afasias motora e sensorial, considerando típica a afasia amnéstica que surge nos abscessos otógenos do lobo temporal, tendo como distúrbio fundamental a dificuldade em encontrar o nome das coisas e pessoas, sem outras perturbações afásicas. Para Nielsen há uma forma leve em que o paciente só tem dificuldade para encontrar nomes próprios; de regra, porém, o doente tem dificuldade em encontrar nomes em geral, recorrendo a perifrases. Em casos mais acentuados também há falhas em relação a verbos, adjetivos e, possivelmente, a tôdas as partes da oração.

Weisenburg e McBride ${ }^{19}$ também salientam a identidade e clareza do distúrbio, que se traduz na dificuldade de encontrar os nomes para os objetos; baseados em 5 casos pessoais, afirmam coexistirem sempre outras perturbações, que incluem no quadro da afasia amnéstica (págs. 299-300): fala extremamente hesitante e inadequada; escrita mais ou menos perturbada; repetição limitada porque as palavras dadas não podem ser retidas por um tempo suficiente. Segundo êstes autores são poucas as alterações das funções intelectuais superiores, da atitude geral e do comportamento. Devemos ressaltar que em nenhum dos 5 casos expostos por Weisenbug e McBride a afasia amnéstica se apresentava isolada e, sim, juntamente com outros sintomas afásicos.

Morel 15 (pág. 107) a considera como fenômeno isolado, primário, dependente de alteração da área 37 de Brodmann, que é chamada "centro" da afasia amnéstica. Leonhard e Sagarra-Sole 11 (pág. 376) propõem que se reserve o nome de amnésia verbal para os distúrbios derivados do déficit da memória de fixaçāo ou da elaboração intelectual para evitar as confusões que vimos referindo.

Kleist 12 relaciona a afasia amnéstica com a surdez nominal, na qual há surdez para o sentido das palavras: as palavras são apreendidas e repetidas segundo soam, não havendo compreensão do sentido do vocábulo. Ambos os fenômenos são relacionados por Kleist a lesões da área 37 de Brodmann. Na afasia amnéstica estão presentes sòmente os distúrbios expressivos, faltando os distúrbios da compreensão das palavras. Kleist explica que a função de compreender nomes depende de ambos os hemisférios cerebrais, enquanto que o processo motor da fala está em relação com o hemisfério esquerdo. Dai o fato de alteraçōes parciais não afetarem a compreensão do sentido dos vocábulos, influindo, no entanto, na procura voluntária dos mesmos.

A nosso ver, não está ainda bem estabelecido o quadro da afasia amnéstica em virtude da ausência de estudos detalhados em casos puros. As conclusões a que chegam os diversos autores se baseiam, quase sempre, em casos com lesōes extensas do cérebro, sendo o estudo do doente feito de modo unilateral, de acôrdo com idéias preconcebidas.. Não há, em geral, a preocupaçāo de isolar os sintomas que seriam concomitantes e não conseqüentes nem determinantes à afasia amnéstica. Não obstante, acreditamos poder afirmar que a opinião mais aceitável sôbre o conceito de afasia am- 
néstica é a que restringe a sua acepção ao distúrbio na formulação de nomes. Ainda não se pode saber com segurança se dêste distúrbio advêm alterações globais do psiquismo pela quebra da harmonia mental, embora nos casos com alterações exclusivas da área 37 de Brodmann, quase sempre tenha sido referida a ausência de tais alterações.

Os demais sintomas arrolados no quadro da afasia amnéstica seriam devidos a alterações em outras áreas e, portanto, apenas concomitantes a êste distúrbio afásico.

Grande interêsse apresentam as afasias amnésticas parciais, chamadas óptica e óptico-táctil (Nielsen 16, pág. 71), nas quais o nome do objeto é encontrado desde que o doente o perceba através de estímulos sensoriais não ópticos, no primeiro caso, e não ópticos nem tácteis, no segundo.

Para finalizar quanto à conceituaçāo da afasia amnéstica, devemos lembrar que ela não deve ser confundida com a afasia nominal de Head, que é um conceito teórico incluindo elementos não só da afasia amnéstica como também da afasia sensorial, havendo não só dificuldade para formulação de nomes como também para a compreensão dos mesmos 8,19 .

Também há certa controvérsia em relação à localizaçāo no cérebro das zonas responsáveis pela afasia amnéstica. A maioria dos autores relaciona os casos de afasia amnéstica às lesões do lobo temporal em sua parte posterior, especialmente na área 37 de Brodmann. A análise da casuistica nem sempre é possivel, por deficiência de dados clínicos e anátomo-patológicos.

Bianchi 2 (pág. 124) conclui que "a uma só região se pode atribuir êste distúrbio afásico: a zona acústica da linguagem". Em outro trabalho ${ }^{3}$ (pág. 111) diz êste autor: "Na afasia amnéstica pròpriamente dita existe sempre um foco, um tumor ou um abscesso, nas proximidades da zona acústica da linguagem ou, nos indivíduos cultos (que, segundo Bianchi falam recorrendo principalmente às imagens visuais), uma lesão nas proximidades do lobo parictal inferior".

Goldstein $^{7}$ (pág. 290), após considerar os distúrbios da memória de evocação e da elaboração intelectual encontrados na arteriosclerose, na paralisia geral e na moléstia de Pick, admite: "Se a afasia amnéstica ocorre numa afecção localizada, esta usualmente diz respeito à região parieto-temporal". Logo a seguir, porém, justificando sua teoria sôbre a origem da afasia amnéstica em um déficit da "atitude de abstração" afirma que "uma lesão da área da palavra sòmente, nunca é seguida de afasia amnéstica". Faz-se necessário, para êste autor, a existência de lesōes difusas do cérebro, fornecendo a causa essencial que seria o déficit da "atitude de abstração". A casuística de Goldstein compōe-se de 5 casos. O primeiro (caso 13, pág. 253), apresentava afasia amnéstica, perseveração e certa tendência à logorréia, tal como no caso que apresentaremos: na anamnese havia referēncia imprecisa de traumatismo; não havia sinais ou sintomas atribuíveis à arteriosclerose, o que é salientado pelo autor que, no entanto, em sua conclusão diagnóstica diz que se tratava de caso de arteriosclerose generalizada, afir- 
mando ter chegado a êste diagnóstico por não haver sinal piramidal nem "outros sintomas". Só dois dos casos de Goldstein foram autopsiados e nos demais casos não são apresentados meios indiretos com o fito de se tentar hipóteses localizatórias.

Weisenburg e McBride ${ }^{19}$ (pág. 318) apresentam 5 casos de afasia amnéstica, sendo três produzidos por tumores e dois por abscessos. Em 4 dos casos o processo se localizava no lobo temporal. No caso restante tratava-se de abscesso do lobo parietal e frontal; a afasia amnéstica, juntamente com rebaixamento mental, crises convulsivas e elementos de afasia motora e talvez sensorial (pág. 562) só surgiu após o ato cirúrgico; os dados apresentados nāo indicam que se tratasse de afasia amnéstica genuina.

Nielsen 15 (pág. 72) reproduz as idéias de Bianchi 2 sôbre a localização das áreas responsáveis pela afasia amnéstica, acrescentando o conceito de área da formulação da linguagem - área 37 de Brodmann - que seria diretamente responsável. Contudo Nielsen afirma que, em alguns casos, pequenas lesões na segunda e terceira circunvoluções temporais, também determinam afasia amnéstica (pág. 127), lembrando, ademais, que nas lobectomias temporais em que a linha de incisão passa adiante da área 37, ocorre invariàvelmente afasia amnéstica devido à interrupção das fibras que dela partem. Para Nielsen também as lesões do istmo temporal invàriavelmente causam o distúrbio em questão, devido ao isolamento total do lobo temporal.

Caso de especial interêsse foi publicado por Williams ${ }^{20}$; tratava-se de paciente que apresentou quadro de afasia amnéstica pura e em cuja autópsia foi encontrada uma área de amolecimento pós-trombose de $1 \mathrm{~cm}$ de diâmetro, localizada diretamente na área 37.

Suter 21 relatou 20 casos de afasia amnéstica, sendo 10 provocados por lesões vasculares, um resultante de abscesso subdural originário do ouvido, um de cisto na extremidade temporal do ventrículo esquerdo e 8 devidos a tumores ou secundários a atos cirúrgicos. Lembra êste autor que, com freqüência, a afasia amnéstica é o primeiro sinal localizatório nos tumores; em sua casuística, $50 \%$ das vêzes tinha sido feito diagnóstico errôneo de afasia motora e em $30 \%$ não havia sido sequer percebida a existência de distúrbios afásicos. Suter atribui tal fato ao desconhecimento dêste tipo de afasia ou à não consideração do mesmo como forma independente das afasias motoras. Quanto à localização cerebral, conclui êste autor: "A afasia amnéstica surge quando uma lesão cortical ou subcortical causa dano a uma região do hemisfério dominante que esteja situada no giro angular ou em suas proximidades".

\section{OBSERVACAO}

A. F. P., com 44 anos de jdade, branco, português, motorista, manidestro, internado em 2-2-1953 (R.G. 55.808). Há 11 anos, teve crise com perda de sentidos quando guiava seu automóvel. A partir de então teve outras crises sempre mais ou menos idênticas: tornava-se pálido, andava para trás até encontrar um obstáculo, com os maxilares fortemente contraidos, um dos bracos estendido para a frente, contrajdo e com movimentos tónico-clónicos; estimulado, emitia palavras sem nexo; após alguns segundos voltava a si, sem noçāo do sucedido. No inicio da moléstia 
não caía ao solo, mas alguns meses após começou a ter vários acidentes por queda brusca e inesperada. Aos poucos foi se tornando irritável e desconfiado, procurando descobrir causas mágicas para sua doença em sessões espiritas e orientando suas suspeitas para a espôsa. Nos últimos seis anos surgiram ciúmes intensos, acompanhados de ameaças de morte e estados de intensa jrritação, em que acusava a espôsa de estar a "fazer mandingas"; chegou a comprar um punhal, investindo contra a espôsa que fugiu para o distrito policial, o que resultou na prisão do paciente. A irritabilidade do paciente se manifestava também fora de casa, gerando freqüentes conflitos.

Ao ser internado verificou-se que o paciente apresentava distúrbios afásicos do tipo de afasia amnéstica. No dia seguinte ao de sua entrada o paciente apresentou-se ligeiramente obnubilado, com reflexos profundos vivos e simétricos, ligeiro desvio da face para a esquerda. Exame de urina, reações sorológlcas para a lues no sangue, hemograma e exame do liqüido cefalorraquidiano resultaram negativos. o exame oftalmológico mostrou edema papilar, com abundantes hemorragias em ambos os olhos. Não foi possivel fazer a campimetria (Dr. Sousa Grota). O paciente foi submetido a angiografia cerebral carotidea à esquerda que mostrou: "Forte desvio para cima do grupo silviano que faz um percurso paralelo ao grupo pericaloso; na incidência de frente nota-se desvio do grupo silviano em direção à linha mediana. Conclusão: tumor no lobo temporal esquerdo" (Dr. Helio Montenegro da Costa).

Após a carótido-angiografja, feita em 16-2-1953, o estado do paciente agravou-se ràpidamente com intensa cefaléia e progressivo estado de torpor. Ao mesmo tempo ocorreram sinais neurológicos focais: hemiparesia flácida à esquerda, desproporcional, sendo mais intensa no membro inferior, sinal de Babinski bilateral, pseudo incontinência de esfincteres. No mesmo dia (16-2-53) foi feita craniotomia para fins de biopsia, sendo verificado intenso edema cerebral, herniando-se o cérebro através da incisão dural. No dia seguinte regrediu o quadro neurológico, voltando o paciente às condiçōes anteriores; também o estado de obnubilaçāo foi cedendo e, poucos dias após, o paciente encontrava-se orientado globalmente, readquirindo o estado de lucidez necessário para exame psíquico mais detalhado. Este quadro manteve-se pràticamente inalterado de março a setembro de 1953, data em que foi submetido à intervenção cirŭrgica; neste periodo é que foi realizado o estudo pormenorizado dos distúrbios de expressão do paciente, que serão relatados mais adiante.

Pelo ato cirúrgico só foi possivel a extirpaçāo parcial do tumor cuja biopsia mostrou tratar-se de astrocitoma misto (Dr. Walter Edgard Maffei). Após a intervençâo cirúrgica sobreveio afasia motora, conservando o paciente a capacidade de compreensão das palavras ouvidas. Alguns dias após, tôda a sua expressão verbal se limitava à palavra isto, acompanhada de um gesto estereotipado com o dedo indicador da māo direita em atitude discursiva. Regrediu parcialmente esta afasia motora, surgindo certas expressōes pornográficas em estado de intensa exaltação emocional, Não se registraram queixas em relação aos sentidos do gósto e do olfato.

O paciente permaneceu internado durante 11 meses, em decadencia progressiva, vindo a falecer em 1-8-1954. O exame anátomo-patológico revelou tratar-se de um astrocitoma protoplasmático, estando o lobo temporal esquerdo totalmente substituido pelo tecido neoplásico que invadia também o lobo parietal e atingia, em profundidade, os núcleos cinzentos da base; por isso o caso não se presta para demonstrar a dependência da afasia amnéstica a alteraçōes restritas da área 37 de Brodmann.

Por ocasião dos exames visando o estudo da afasia submetemos o paciente ao teste de Rorschach, que produziu 33 respostas no tempo de 33 minutos, com extensa faixa de determinantes, a saber: uma resposta de movimento animal e uma de movimento inanimado, como adicionais; duas de perspectiva com o elemento forma como primário na associação e duas como adicionais; duas de luminosidade, com forma bem delimitada e mais duas adicionais do mesmo tipo; uma adicional de relevo e uma adicional de transparência; uma de forma-côr e uma adicional de côr-forma. Houve duas respostas com contaminação e estiveram presentes 5 sinais de Piotrowski, indicativos de lesōes cerebrais, a saber: ausência de $M$, frases 
estereotipadas de pré-enchimento, perplexidade, perseveracão e vulgares em $11 \%$. A dificuldade em nomear só se manifestou em $30 \%$ das respostas.

Faremos, a seguir, uma súmula dos exames psiquicos especialmente visando os distúrbios de expressão, realizados no periodo de 6 meses em que o paciente se mostrava lúcido:

Exame psiquico - $\mathrm{O}$ paciente nos procurava diăriamente, a fim de solicitar sua alta hospitalar, em atitude amigável e respeitosa, embora veemente; logo passava a dirigir invectivas à espôsa, repetindo sempre as mesmas acusações, Em geral alegre, por vêzes se comovia fàcilmente indo até ao chôro. Tinha perfeita noção do tempo e do ambiente, porém a noção de moléstia era sơmente parcial, tendendo a atribuir a sua internação a perseguição por parte da familia. Reconhecia, no entanto, que tinha na cabeça algo que provocara as crises, a cefaléia e o "esquecimento". Em alguns períodos de melhora sentia-se perfeitamente normal, nunca chegando a compreender in totum sua verdadeira situação, o que o levaria a reivindicar sua saida de modo mais adequado. Convencia-se fáciimente com nossas promessas diárias de permitir sua alta. Vivia os problemas principals de sua existência em relação ao desquite de sua espôsa, às suas propriedades, chegando mesmo a formular certos planos para o futuro. Pelo confronto com seu comportamento anterior à moléstia, conforme foi referido pela espôsa, tornavam-se nitidas certas modificações de personalidade: crises de irritabilidade, tendência a humor alegre e labilidade de humor, excitação verbal, tendência à perseveração, redução da iniciativa pragmática, déficjt ligeiro da capacidade de elaboraçāo intelectual, idéias persecutórias.

\section{Exame da linguagem:}

Linguagem espontànea - A uma pergunta nossa o paciente põe-se a falar quase ininterruptamente, obrigando-nos muitas vêzes a interrompê-lo; os temas são sempre os mesmos, relativos à sua situação no hospital, invectivas contra a espôsa, recordaçōes de intenso conteúdo afetivo, sempre com muita veemência. Por vêzes se detém na procura de uma palavra, parecendo que a substitui por outra, mas sempre de modo adequado, sem parafasias. A construção da frase é correta e inclui, em geral, oracōes coordenadas e subordinadas.

Compreensão da linguagem - O paciente compreende prontamente ordens simples. Ordens tais como a de colocar a māo direita na orelha esquerda precisam ser repetidas várias vêzes, executando-as afinal corretamente. Aponta logo os objetos cujos nomes lhe damos, e também as partes de seu corpo. Entende conceitos abstratos (covardia, virtude), tendo dificuldade para elaborar exemplos. $\AA$ pergunta sóbre a diferença entre um quilo de algodāo e um quilo de chumbo, responde corretamente. Nāo consegue esclarecer o brocardo: "Agua mole em pedra dura tanto bate até que fura".

Encontro da palavra adequada - Em geral não consegue nomear os objetos de uso corrente, procurando então definílos pelo uso. Tem noção desta dificuldade, atribuindo-a à falta de memória. Nesta pesquisa que se repetiu várias vêzes, sòmente em duas respostas poderfamos considerar a substituição por palavra inadequada; posslvelmente não se tratou de parafasia. Mesmo tomando o objeto entre as mãos ou ouvindo sons produzidos pelo mesmo, nāo encontra o paciente o nome correspondente; entretanto, logo que se diz o nome do objeto, prontamente o reconhece e repete. Se o ajudamos dizendo as sillabas iniciais, muitas vêzes consegue encontrar o nome.

Repeticão das palavras - Repete, com facilidade, palavras usuais ou não.

Linguagem seriada - Conta com desenvoltura de 1 a $10 \mathrm{e}$, com certa difjculdade, na ordem inversa. O mesmo se verifica em relação aos dias da semana aos meses. 
Escrita - Conservada, dentro das limitaçōes de seu grau de cultura, tanto a espontânea como o ditado e a cópia.

Leitura - Conservada a capacidade de leitura.

Cálculo - Realiza as operações de adição e subtração, na ordem correta, transportando os números de ordem, mas cometendo alguns érros de tabuada.

Praxia - O paciente copia figuras geométricas em várias posições (círculos, quadrados, retângulos, triángulos, paralelas). Executa movimentos complexos. Presentes as noçōes de direita e esquerda no espaço e no próprio corpo. Em relação ao reconhecimento de côres, apresenta dificuldades acentuadas para nomeá-las, porém as distingue quando recebe ordens verbais.

Apresentamos a seguir excertos do diálogo que mantivemos com o paciente, que foi gravado em disco, mostrando o tipo dos distúrbios afásicos amnésticos:

$P$ - Que objeto é êste? (caneta-tinteiro)

$R$ - Isso ai é uma caneta-tinteiro, é sim senhor.

$P$ - E êste? (lapiseira)

$R$ - Isso daí é, é uma pena, é uma caneta para se escrever.

$P$ - Veja bem.

$R$ - E uma caneta, olha aqui doutor eu acho que é uma caneta. Pelo que vejo acho que é uma caneta, pelo jeito deve ser uma caneta.

$P$ - E isto? (relógio de pulso)

$R$ - Isso dai é... é... isso dai é... isso daì é... é uma colsa de se lomar... é uma coisa de pôr aqui... de pôr aqui no punho... não é?... e depois ver que horas sāo.

$P$ - Qual É o nome dêsse objeto?

$R$ - Justamente, doutor, é isso que o senhor escreveu agora. Isso daí é... eu já esqueci o nome... isso daí é para tomar nota das horas que são.

$P$ - Mas o nome do objeto como é?

$R$ - Esse objeto é um... é um... como é que se diz?... é um... é um...

$P$ - O senhor tem êsse objeto? O senhor não usa êsse objeto? ou nunca usou?

$R-$ Eu nunca usef. Porque nunca pude comprar.

$P$ - No seu automóvel não tînha isso?

$R$ - Não, senhor. No automóvel igual a êste... não tìnha, tinha quilometragem: $1,2,3,4,7,8,10 \ldots$

$P$ - Mas, então o senhor não sabe o nome désse objeto que o senhor descreveu para marcar hora?

$R$ - Isso daí é... eu nunca usei isso.

$P$ - É um relógio?

$R$ - Isso é um relógio de marcar hora.

$P$ - Mas o senhor nāo se lembrava do nome?

$R$ - Não, porque eu nunca useí.

$P$ - Vou mostrar outro objeto. O que é isto? (moeda)

$R$ - Isso daí é dinheiro, dinheiro de prata ou de niquel.

$P$ - Que quantia de dinheiro representa isso?

$R$ - Dois mil réis.

$P$ - O que é isto? (chave) 


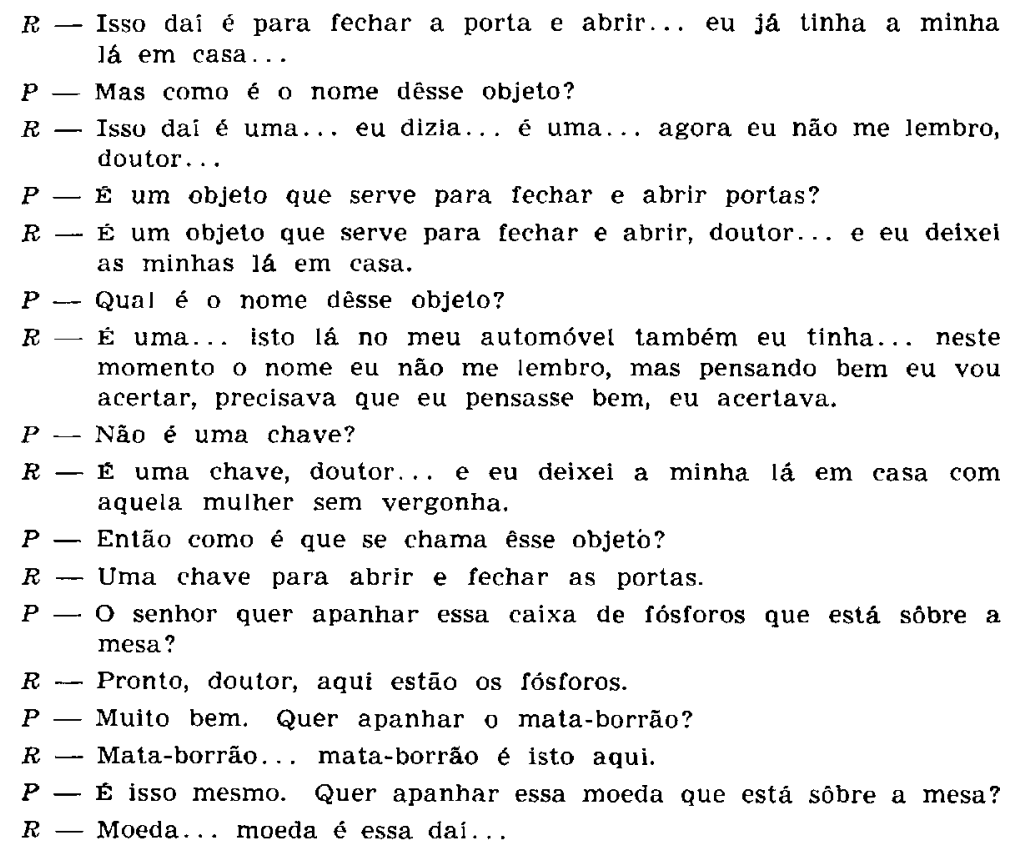

\section{COMENTARIOS}

Nenhuma das teorias que procuram explicar o distürbio essencial da afasia amnéstica é plenamente satisfatória. A teoria de Goldstein ${ }^{7}$ não está de acôrdo com os dados objetivos. Schilder ${ }^{18}$ e Morel ${ }^{1 \bar{s}}$ consideram a afasia amnéstica como distúrbio apráxico da palavra, comparando-a à apraxia ideo-motora. Bianchi explica até certo ponto a existência de afasias amnésticas ópticas e óptico-tácteis, supondo lesōes de carảter inibidor nas proximidades das correspondentes áreas sensoriais.

Há muita especulação teórica que nos parece não trazer qualquer progresso ao melhor conhecimento do assunto, pois faltam dados objetivos. Os casos puros e bem estudados são poucos e os de afasias amnésticas parciais (ópticas e óptico-tácteis) são raros. Parece-nos que as conclusóes que se podem tirar dos fatos até agora apurados, sujeitos a revisões diante de novos elementos, são as seguintes:

a) Os casos puros de afasia amnéstica são todos, direta ou indiretamente, relacionados com a área 37 de Brodmann do hemisfério esquerdo nos manidestros;

b) A função de nomear objetos ou conceitos parece ser básica do psiquismo humano. Pode ser afetada secundàriamente por distúrbios da compreensão ou da expressão verbal, como nas afasias sensoriais ou motoras, 
e por déficit da memória ou de elaboração intelectual, como nos quadros mentais em que essas funções são afetadas;

c) O déficit da função de encontro de nomes afeta as funçōes de abstração, pois esta se faz na base dos simbolos que são representados pelas palavras;

d) A existência de afasias amnésticas parciais, isto é, que só se verificam quando o estímulo sensorial depende de um ou de dois sentidos, demonstra que a função em questāo é, de certa maneira e de modo independente, ligada a cada esfera sensorial;

e) A diferença essencial entre a linguagem espontânea e a que se faz a partir de estímulos sensoriais externos é que, no primeiro caso, a origem do estímulo é a representação mental e, no segundo, são as imagens scnsoriais, oriundas do mundo externo;

f) O teste de Rorschach - apesar do nosso paciente apresentar outras perturbações do psiquismo e portanto não se prestar idealmente para esta pesquisa - demonstrou que o déficit de nomear afeta em grau reduzido a elaboração intelectual; provàvelmente, porque os estímulos recebidos das manchas são elementares e só uīteriormente são coordenados mediante elaboração intelectual, chegando assim o paciente a encontrar mais fàcilmente o nome correspondente ao conceito que elaborou.

\section{RESUMO}

Após breve recapitulação dos conceitos sôbre a afasia amnéstica, os autores salientam a necessidade de tomar como ponto de partida, para o estudo dêsse distúrbio, os casos em que êle se apresente em forma pura, isto é, sem outros distúrbios da expressão; nesse sentido procuram diferençar a afasia amnéstica de outras perturbações afásicas, aparentemente análogas mas essencialmente diversas.

Apresentam um caso de afasìa amnéstica pura em paciente portador de astrocitoma que invadia a parte posterior do lobo temporal esquerdo, inclusive a área 37 de Brodmann, área cuja lesão é considerada como responsável por êsse tipo de distúrbio afásico; além do estudo da expressão oral e escrita, assim como da praxia e da gnosia, foi feito o psicodiagnóstico de Rorschach.

\section{SUMMARY}

\section{Amnestic aphasia: case report}

After brief historical review about the concepts on amnestic aphasia the authors emphasize the need to consider as a starting point the cases in which this disturbance presents itself in a pure form; in this sense they 
try to differentiate the amnestic aphasia from other aphasic disturbances, seemingly analogous but essentially different.

A case of pure amnestic aphasia is reported in a patient with an astrocitoma at the posterior part of left temporal lobe, including Brodmann's area 37 which lesion is responsible for this type of aphasic disturbance; besides the study of the patient's verbal and writing expressions, of gnosia and praxia, the authors applied the Rorschach test.

\section{REFERENCIAS}

1. AJURIAguerRA, J.; HECAEN, H. - Le Cortex Cérébral. Etude Neuropsychopathologique. Masson et Cie., Paris, 1949. 2. BIANCHI, L. — Lições sobre Localizações Cerebrais e Physiopathologia da Linguagem. Laemmert \& Cia., Rio de Janeiro, 1899. 3. BIANCHI, L. - L'afasia amnestica. Ann. de Nevrol., 32:99-119, 1914. 4. EAGLETON, W. P. - Brain Abscess. MacMillan Co., Nova York, 1924. 5. FREUD, S. - On Aphasia: a Critical Study. International Universities Press Inc., Nova York, 1953. 6. FREUD, E. D. - Recent trends in aphasic research. Am. Psychiat., 110:180-193, 1953. 7. GOLDSTEIN, K. - Language and Language Disturbances. Grune \& Stratton, Nova York, 1948. 8. HEAD, H. - Aphasia and Kindred Disorders of Speech. University Press, Cambridge, 1926. 9. JAKOB, C. Sistema Nervoso (Anatomia, Semiotica e Petologia). Società Editrice Libraria, Milão, 1899. 10. KANZER, M. - Early symptoms of aphasia with brain tumors. J. Nerv. a. Mental Dis., 95:702-720, 1942. 11. LEONHARD, K.; SAGARRA-SOLE, J. Manual de Psiquiatria. Ed. Morata, Madrid, 1953. 12. KLEIST, K. - Gehirnpathologie. Johann Ambrosius Barth, Leipzig, 1934. 13. KRAEPELIN, E. - Trattato di Psichiatria. Trad. italiana, vol. 1, Francesco Vallardi, Milão, s/data. 14. MONAKOW, C. V.; MOURGUE, R. - Introduction Biologique à l'Etude de la Neurologie e de la Psychopathologie. Librarie Fêlix Alcan, Paris, 1928. 15. MOREL, F. - Irtroduction à la Psychiatrie Neurologique. Masson et Cie., Paris, 1947. 16. NIELSEN, J. M. - Agnosia, Apraxia, Aphasia: their Value in Cerebral Localization, 2nd ed. Paul B. Hoeber Ine., Nova York-Londres, 1946. 17. NIELSEN, J. M. - Textbook of Clinical Neurology, 3rd ed. Paul B. Hoeber Ine., Nova York, 1951. 18. SCHILDER, P. - The Image and Appearance of the Human Body. Psychol. Monogr. no 4. Paul Kegan. Trench, Trubner \& Co., Londres, 1935. 19. WEISENBURG, Th.; McBRIDE, K, E. - Aphasia: a Clinical and Psychological Study. Commonwealth Fund, Nova York, 1935. 20. WILliAMS, R. R. - Case of amnesic aphasia with focal lesion in area 37. Bull. Los Angeles Neurol. Soc., 10:75-80, 1945. 21. SUTTER, C. - Anomic aphasia. J.A.M.A., 151:462-468, 1953.

Hospital de Juqueri - Franco da Rocha - São Paulo, Brasil. 